waited until the os uteri was dilated to the size of a half crown-piece, then gave her from a scruple to a balf drachm of the powder; when the patient was delivered there was not more than the ordinary hamorrhage; and in lieu of her suffering from extreme debility, retention of the lochia, \&c., (which invariably was the case) was enabled to follow her domestic pursuits within the accustomed time.

Out of innumerable cases of labour, when I have given the secale cornutum, serious hæmorrhage never occurred in a single instance.

I found, from observation, that when $I$ gave smaller doses than a scruple I was foiled in my expectations; and that instead of producing an expulsive contraction, the uteus would remain tranquil. I generally give from a scruple to half a drachm, and repeat the dose every quarter of an hour, until evident signs of contraction take place.

I should certainly not think of giving it wntil the os uteri was dilated sufficiently to ascertain the presentation; neither in unna. tural presentation, or where there was rigidity of the os uleri, unavoidable hæmorrhage, \&c. I have found the following formula very beneficial in chlorosis, and also in leucorrhoea :-

Aloetic pill, 1 grain;

Pouder of the secale cornutum, 2 grains. To be taken twice a day. Should uterine hemorrhage continue, after the cessation of the lochia, I have always checked its discharge, by giving the patient from 5 to 10 grains three times a day in milk, at the same time giving bitter infusions, \&c.

I am aware that theoretical men are decidedly opposed to the administration of the secale cornutum; yet it gives me great pleasure to find that its value is appreciated by eminent practitioners in midwifery, and I have no doubt ere long it will be valued by those who think light of its use now, especially when three or four hours sleep can be obtained by its use, in causing speedy and safe delivery, instead of waiting anxiously by the bedside of the patient.

\section{CASE OF SCARLATINA TREATED ON THE TONIC PLAN.}

B Y J. S U T T O N, EsQ,

ON the 23rd of October I was called to see a boy living in Windsor court, Strand, whose sister was just recovering from an attack of Scarlatina Anginosa, marked by symptoms of peculiar severity, assuming at the latter part the typhoid form, and attended by otitis and subsequent caries of the temporal bone. I found my patient, a boy of 12 or 13 years of age, thin but muscular, and with a temperament decidedly san- guineous, complaining of a sore throat, which, on inspection, presented a dusky red hue, great pain in the head, and intolerance of light and sound. The tongue was furred, and the abdomen was of a higher temperament than natural, and the bowels confined. The pulse ranged as high as 130 , full and hard. An emetic was given, and followed by an aperient in a few hours. On my visit, the following morning, I found the symptoms precisely the same, and, in addition, patches of the efflorescence about the face and neck. His sister, a girl of a plethoric habit of body, 17 years of age, had the previous erening a rigor, \&ce, and then presented similar symptoms. An emetic was given to her, followed by an aperient, and on my visit the next morning (25th), I found in each the following symptoms: skin hot, dry, and covered with the eruption; constant restlessness, with occasional delirium; tongue red at the tip, and corered with a dirty white fur; lips dry and parched; and the teeth covered with a peculiar varnish. The urine was small in quantity, high coloured, and occasioned considerabie scalding whilst being passed. The pulse was 140 in each case, hard and bounding, and there was great throbbing of the carotids. They both complained much of their throats, which, on inspection, were found to have the tongils much swollen, and several small specks of ulceration on them. The tepid ablutions which I had ordered at the beginning, were still to be continued, and the following mixture was given :-

Disulph. of quinine, gr. xij.

Dilute. sulphur. acid, Mxx.

Comp spirit of lavand. $3 \mathrm{i}$.

Water $\xi \mathrm{vj.} \mathrm{A} \mathrm{little} \mathrm{wine} \mathrm{occaionally.}$ Of this mixture the boy had one tablespoonful every four hours.

On the 26th, I found the symptoms in both much amended; but in the boy a greater change than I imagined possible, in so short a time, has taken place. His tongue is much cleaner and moist; howels have been relievcd; and his skin is cool and covered with perspiration. The pulse is 90, full and soft; perfectly calm and collected in his manner, and is able to swallow much better. The girl presents nearly the same symptoms, and is able to sit up and bear the exposure to light. She complains, however, of pain lower down in the throat, but on inspection, the redness is not so ap. parent, and the small ash-coloured specks have some of them disappeared. They were both ordered beef tea and the wine as yesterday.

At my visit on the 27 th, I found the boy with a tranquil pulse, cool skin, profuse expectoration, and secretion of urine, and the throat much betfer. The eruption has left the skin, and there is not a single bad symp. tom remaining. The girl is not so well; 
there is a considerable accession of fever, and a dusky hue of the face, which, joined to a slightly stridulous sound in the bigher tones of the voice, and a purple appearance of the tongue, an appearance which $I$ have often noticed, led me to suspect the existence of bronchitis, although as yet in a very slight degree. I ordered a powder, contain. ing 10 grs. of hydr. cum. creta, and half a grain of opium every four hours. The wine and quinine were of course not persisted in.

$28 \mathrm{th}$. The boy is still improving; the girl better, but not entirely free from the bronchial symptoms. The skin, however, is cool, and the face has lost the dusky hue which it presented yesterday. The pulse is 80 and soft, and there is no pain, except in the head, and a little uneasiness in the stomach, cansed perhaps by the quinine, which was again ordered, althongh in smaller doses.

29 th. The boy is rapidly recuvering, and the girl, with the exception of the pain in the head, for which small blisters behind the ears were ordered, has not a single bad symptom.

31st. Both are in a state of convalescence.

Jan. 2, 1840.

\section{TH E LA N C ET.}

\section{London, Saturday, January, 18, 1840.}

To continue the review of the present state of the question of Medical Reform, we must revert to the Corporations. Medical science, though divided into departments, is essentially one, and the Corporations should strengthen the bond of union, which distance, time, dissimilarity of practice, and inequality of fortune, tend to sever. Good will would this be fostered. The labours of inquirers would radiate to a centre, and throw a reciprocal light upon the whole world of science. But the Medical Corporations, instead of promoting harmony, have introduced inextricable confusion into the profession. The inmense majority of the members are "cyphers, if not aliens." They are "so regarded by the self-elective Councils." They have no voice, no power, in the Corporations to which they are nominally attached. An eternal bar shuts them out from all offices of honour or emolument. Talent is dle-industry is vain. The stimulus, which stirs generous minds in other careers is with. held. The Sydenhams and the Jenners may confer endless blessings upon the com. munity, and pass through life unrecognised, undistinguished ; without a place, name, or rank, in the Councils of the Corporations. We have now a Marshall Hall and a Clarke, licentiates ; Grant, Carswell, and Sharpey, unlicensed; a Francis Hawkins, Registrar, a Halford, President, of the Roy al College of Physicians. A small knot of self-elective, irresponsible, nnscrupulous men seat themselves in the Councils for life, and regard the thousands of their brethren with contempt; or, at the top of their chartered voices call them " CY PHERs, if not ALIENs,"-a sound which must now ring through the land, and may, perhaps, reverberate in thunders through the College Halls. The 300 licen. tiates will hear it, the 10,000 members of the College of Surgeons will hear it, it will strike the ears of general practitioners in every part of the kingdom-the "CYPHERs, if not ALIENS"!

The arbitrary governing bodies cut them. selves off from the commonalty. They carry on their proceedings in secret. They expend the money of the members. They pass by. laws in their own favour, and throw iniquitous monopolies into the hands of their creatures. And they do this under the pre. sent charters and laws.

The profession is not only disturbed by the isolation of the governing bodies from the governed, but it is further deprived of all efficiency and useful influence, by the subdivision into several licensing bodies; conferring the same title after the application of different tests, and different titles and ranks after the same or similar examinations. In London, the College of Phy. sicians examines only in physic, excluding what is called surgery from pathology, as well as from therapentics. Its licentiates are bound to abjure the practice of surgery By the by-laws no accouclieurs could be. come Fellows of the College. Sir Cuarles Mansfield Clarke, accoucheur, by grace, of the Iadies, and physician, by grace, of his 